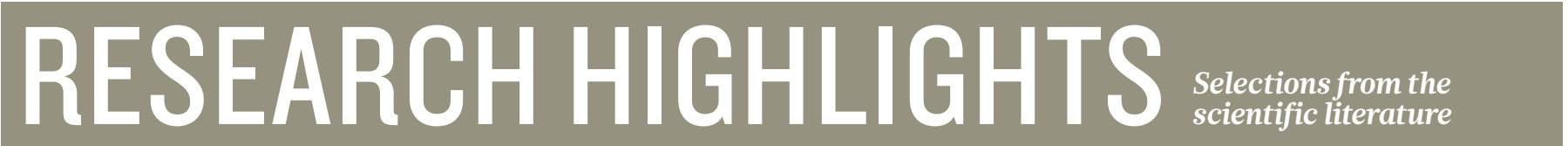

CULTURE

\section{Religion as cuckoldry defence}

How can patriarchal societies be sure that the men who inherit their fathers' goods are actually their fathers' sons? Religions help men to be more confident in their paternity by setting standards for female sexual behaviour.

Beverly Strassmann at the University of Michigan in Ann Arbor and her team studied genetic data from 1,706 fatherson pairs among the Dogon of Mali. Although many Dogon are Christian or Muslim, the adherents of their indigenous religion had the lowest rate of male births due to cuckoldry: $1.3 \%$ versus $2.9 \%$ for the other faiths. The researchers chalk this up to the traditional huts where menstruating women must spend their nights. In a society in which women are often pregnant or unable to conceive owing to intensive breast-feeding, a sojourn in the hut informs a woman's husband and his kin that she has become fertile again. The family can then increase their vigilance towards her.

Proc. Natl Acad. Sci. USA

http://dx.doi.org/10.1073/

pnas.1110442109 (2012)

BIOMIMETICS

\section{Synthetic silk inspired by insect}

The green lacewing (Mallada signata), an insect used in biological pest control, has inspired the creation of an artificial silk.

To protect its progeny from predators, the female lacewing suspends its eggs from the underside of a leaf using a thin silk stalk of remarkable tensile strength. To forge a similar stalk, Thomas Scheibel and Felix Bauer at the University

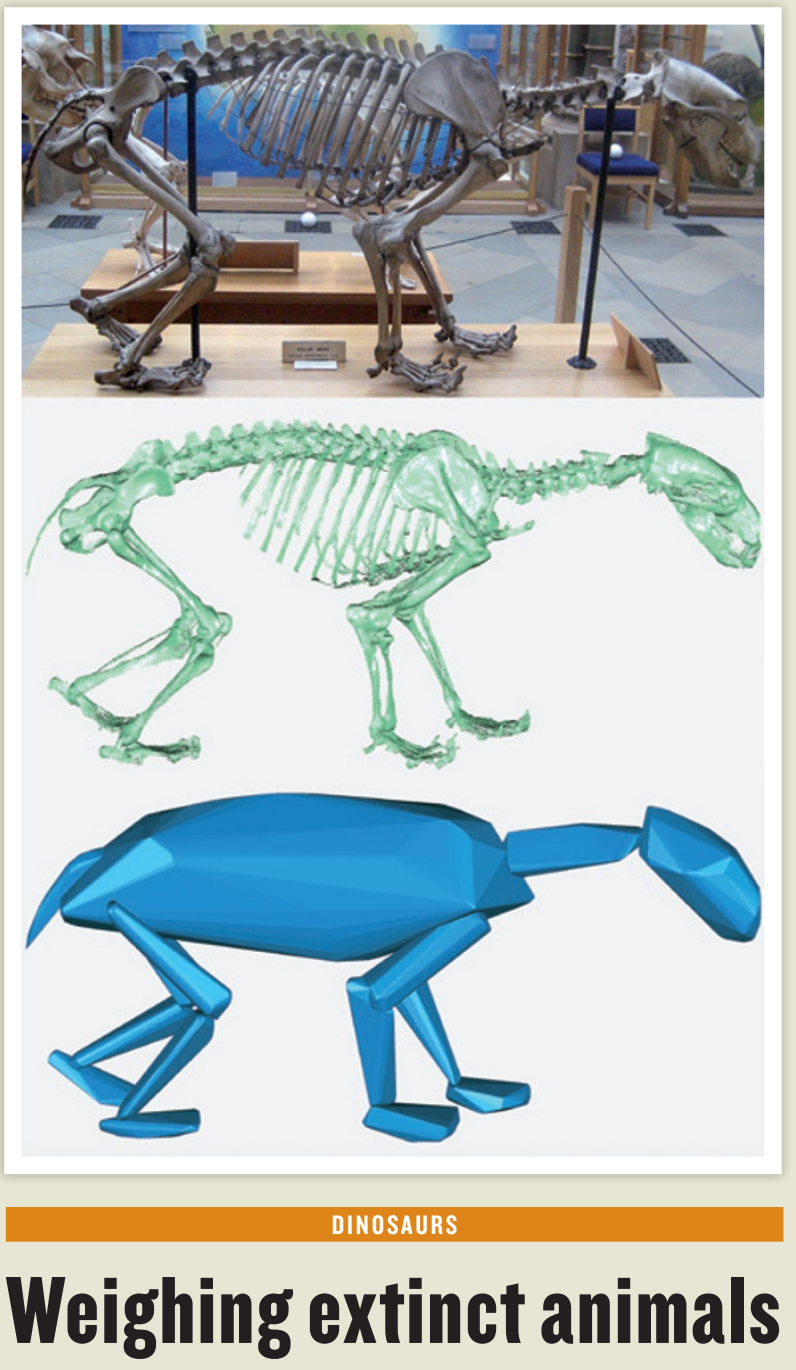

Knowing an extinct animal's mass is crucial for estimating its physiological traits but the standard technique - in which a model of the animal is made and its mass then calculated from its density - has been criticized for being too subjective.

Bill Sellers at the University of Manchester, UK, and his team laser-scanned the skeletons of 14 large mammals, including the bison and the elephant. The researchers used the scans to mathematically derive 'convex hulls' of the bones - the minimum volume that encloses a set of points, akin to gift-wrapping a teapot - and converted these volumes into estimates of mass. These were then compared to the known values.

The method consistently underestimated true body mass by $21 \%$. Thus, using this method and then adding $21 \%$ should provide more accurate predictions. When the team used the corrected technique on Giraffatitan brancai, one of the largest dinosaur skeletons in the world, the beast clocked in at 23,200 kilograms, similar to recent volumetric estimates. Biol. Lett. http://dx.doi.org/10.1098/rsbl.2012.0263 (2012) of Bayreuth in Germany developed a synthetic protein based on a repeating aminoacid pattern found in one of the proteins in lacewing silk. The researchers introduced a synthetic gene that codes for the protein into Escherichia coli bacteria.

Filaments of the bacteriaproduced silk proved to be almost as strong as natural lacewing silk, except at high humidity, and more elastic.

Angew. Chem. Int. Edn. http://dx.doi.org/10.1002/ anie.201200591 (2012)

\section{ZOOLOGY}

\section{Live birth without a placenta}

Some sharks and rays give birth to live young but lack placentas or umbilical cords. So how do their embryos obtain oxygen?

Taketeru Tomita of the Hokkaido University Museum in Hakodate, Japan, and his team used ultrasound to study a pregnant manta ray (Manta alfredi) to find out. They found that the embryo rhythmically raises and lowers its jaw, pumping uterine fluid into its mouth and through holes behind its eyes called spiracles. After birth, the spiracles shrink as the animal becomes able to force water over its gills by swimming.

Biol. Lett. http://dx.doi. org/10.1098/rsbl.2012.0288 (2012)

DRUG DISCOVERY

\section{Melanoma} pathway targeted

A drug that targets the RAS signalling cascade - which is thought to drive tumour growth in $20 \%$ of cancers improves survival in some patients with advanced melanoma. 
The drug, called trametinib, inhibits MEK, a protein that amplifies cancer-promoting signals. Keith Flaherty at the Massachusetts General Hospital in Boston and his team tested trametinib in melanoma patients with a mutated version of a RASpathway protein BRAF, which is mutated in $50 \%$ of advanced melanoma patients. A total of 322 patients were randomly assigned to receive either trametinib or standard chemotherapy.

Twenty-two percent of patients responded to trametinib, which delayed disease progression by 3 months longer than chemotherapy alone. N. Engl. J. Med. http://dx.doi. org/10.1056/nejmoa1203421 (2012)

\section{ARCHAEOLOGY}

\section{Cultural wellspring}

Certain forms of art and music might have emerged among ancient humans living in southern Germany and then spread through Europe along the Danube River.

The Aurignacian culture, which is characterized by innovations such as figurative art and musical instruments (mammoth-ivory flute pictured), originated in Europe more than 40,000 years ago. However, imprecision in carbon dating has made it difficult to determine precisely where the culture arose. Thomas Higham at the University of Oxford, UK, Nicholas Conard at the University of Tübingen, Germany, and their team used improved sample preparation techniques for carbon dating to study Aurignacian remains from Geißenklösterle cave in southern Germany's Swabian Jura region.

The analysis revealed that the artefacts at Geißenklösterle are about 42,500 years old. This pre-dates other recently dated Aurignacian sites in Europe.

J. Hum. Evol. http://dx.doi. org/10.1016/j.jhevol.2012.03.003 (2012)

\section{EXTRASOLAR PLANETS}

\section{A new world}

\section{is born}

Astronomers have identified a planet in the making.

The variable brightness of GM Cephei - a 4-millionyear-old star 870 parsecs away - has been noted for decades. But whether that variability is caused by bursts of light from the star or by an object in the disk of dust that surrounds it has been a matter of debate.

Wen-Ping Chen at the National Central University in Jhongli, Taiwan, and his team argue for the latter. Using telescopes positioned around the world, the researchers monitored GM Cephei from 2009 to 2011 and found that the brightness of the star dipped each year for about a month. The researchers interpret this variability as evidence of a young planet: a clump of dust, roughly the mass of an asteroid, which is orbiting GM Cephei.

Astrophys. J. 751: 118 (2012)

\section{METABOLISM}

\section{A pathway for feeding control}

The activation of a group of neurons in a region of the brain called the hypothalamus boosts food intake, but what controls this activation has been unclear. Researchers have now identified a receptor in these neurons that is targeted by a protein called FoxO1 to promote feeding.

The FoxO1 protein is involved in regulating the signalling of key hormones that suppress appetite. Domenico Accili at Columbia University in New York and his team deleted FoxO1 from mouse hypothalamic neurons

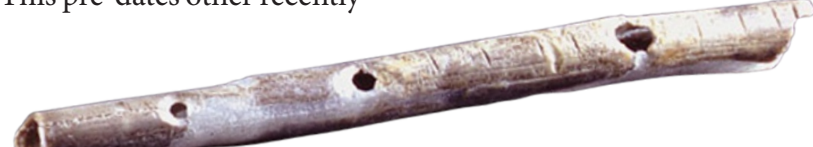

\section{and found that the animals} were leaner, ate less and had improved glucose and fat metabolism compared with normal mice. The researchers pinpointed the receptor Gpr17 as mediating the effects of FoxO1.

Targeting this pathway could be a strategy for anti-obesity drugs, the authors say. Cell 149, 1314-1326(2012)

\section{Ship GPS could flag tsunamis}

Commercial ships on Earth's oceans could provide a cheap and easy way to track propagating tsunamis.

Current warning systems rely on sparse, expensive buoys and underwater sensors that track a wave once it has been triggered by an earthquake. James Foster at the University of Hawaii at Manoa in Honolulu and his team examined Global Positioning System (GPS) data from a research vessel (pictured) that was heading from Hawaii to Guam in February 2010 when
The most viewed papers in science

\section{EVOLUTION}

\section{Domesticated apes}

Selection against aggression seems to have occurred naturally in some animals and to have led to traits similar to those seen in domesticated animals.

The bonobo (Pan paniscus) is

less aggressive and more sociable than its sister species, the bonobos have smaller childlike heads, plus paler lips and tails, than chimps - are a linked set of traits that parallel those seen in domesticated animals such as dogs and guineapigs. Bonobos are, the authors argue, a self-domesticated ape. 作 reducing competition for food and the emergence of cemales that enforced the peace. also occur spontaneously in nature, they say. Anim. Behav. 83, 573-585 (2012)

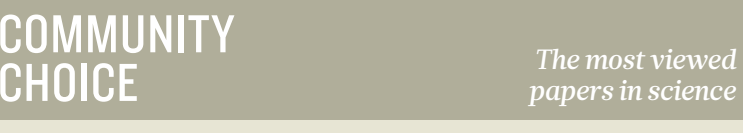

\section{.}

HIGHLY READ

on journals.elsevier. com/animal-hehaviour March-May

.

